\title{
Defining the Social Economy and its Governance at the Neighbourhood Level: A Methodological Reflection
}

\author{
Frank Moulaert and Jacques Nussbaumer
}

[Paper first received, June 2004; in final form, June 2005]

\begin{abstract}
Summary. This largely methodological paper focuses on how to define the social economy and its governance at the local and especially the urban neighbourhood level. A distinction is made between essentialist and holistic definitions. The second section appraises the potential contribution of various current ideas in institutional economics and economic sociology to the definition of the social economy and its governance. It is found that 'old' and 'new' institutionalism in particular offer useful tools, including the holistic methodology as applied by John Commons. The third section elaborates on the analytical elements required for defining the social economy from a holistic perspective, stressing the role of essentialist abstract categories, the role of local culture and articulation between spatial scales. First, we show how the notion of social capital defined through a 'holistic approach' can enrich the definition of the social economy. Secondly, we stress the importance of empirical investigations in feeding into the holistic definitional work. The fourth section concludes the paper by enhancing the necessary dialogue between an abstract-essentialist and a contextualised holistic definition of the social economy at the neighbourhood level.
\end{abstract}

1. How to Define the Social Economy: Methodological Stance

The purpose of this paper is to define the social economy at the local level, especially from a holistic perspective. The social economy is considered as part of social innovation-see the introduction to this Special Topic. According to Moulaert et al. (2002), social innovation at the local level rests on two pillars: institutional innovation (innovation in social relations, innovations in governance including empowerment dynamics) ${ }^{1}$ and innovation in the sense of the social economy-i.e. satisfaction of various needs in local communities (Schmoller, 1905;
Moulaert et al., 1992; Nussbaumer, 2002; Moulaert et al., 2000). Yet both pillars are intimately related.

Institutional innovation has a purpose of its own. It includes and vehicles cultural emancipation, interpersonal and intergroup communication, preference revealing and decision-making mechanisms, systems development and co-ordination, all basic elements of community dynamics, empowerment and organisation of the local (social) economy, including its employment relations. Relevant sub-systems of the economy at the community level belong to the production and allocation spheres and are continuously or recurrently 
in search for institutional innovation (Moulaert et al., 2000).

But institutional innovation, especially in revealing preferences, in decision-making and in systems co-ordination, is a conditio sine qua non for basic needs satisfaction. Without these types of institutional innovation, new (social economy) production and allocation initiatives cannot be grounded in community dynamics and will be alienated from community needs; from this perspective, institutional innovation is connected to evolution and creativity in facing collective demands.

Generally speaking, satisfaction of 'basic' needs not only covers food, clothing, good health and shelter, but also the autonomy or self-determination of individuals who require education, health and good governance. From this point of view, institutional innovation belongs to the core agenda of social innovation through the satisfaction of basic human needs. How significant a role it plays will depend on a number of factors such as: the contextual hierarchy of needs (place of materiality in preference scale, absolute character of primary needs_- "Erst kommt das Fressen, dann kommt die Moral"-citing B. Brecht's 'Ballade vom Angenehmen Leben'), the democratic content of local culture.

How then are we to define the local social economy, taking into account this intrinsic interweaving of needs satisfaction and institutional innovation? To this end, the paper addresses at least two challenges.

First, it presupposes awareness that any definition of the local social economy should account for the varying generic features discovered in the survey of the literature discussed earlier in this issue (Moulaert and Ailenei, this issue): institutional-political dimensions (from an historical perspective); property and control relations; type of 'core' agent; market orientation; model of co-operation; needs satisfaction system (production, allocation). In addition, as we are concerned with the 'local' — and in many cases the 'neighbourhood' economy-spatial scales and their articulation should be included in this list of generic features.
Secondly, there is the question of paradigmatic choices. Which are the most relevant research questions? Which theoretical traditions should be mobilised? Although, $a$ priori, we keep an open mind on all theories which integrate social justice within their view of human and economic progress, we highlight institutional paradigms and theories. These attach more value to contextual and historical analysis, which Moulaert and Ailenei (this issue) believe to be essential in any relevant conceptualisation of the social economy. In addition, and aware of significant differences between them, there is room for analysing norm-setting within institutional theories.

The paper weighs up the potential of institutional-economic theories in particular for facing these challenges and for conceptualising the social economy in both its interconnected dimensions: institutional innovation and innovation in needs satisfaction. To this end, the following methodological position is adopted. A fundamental distinction is made between an essentialist and a holist definition. An essentialist definition uses abstract categories only, claiming generality for a variety of specific situations (i.e. historical epochs, territorial dynamics, institutional contexts). It is typical of idealist-positivist paradigms, such as neo-classical and neoinstitutional economics or sociology. A holistic definition in contrast does not pursue generality, but inclusiveness. A holistic theory focuses on the dialectics of general mechanisms and factors of explanation on the one hand, and specific situations on the other. And as the holistic approach is indebted to the American pragmatist school, it recognises the intimate relationship between theory building and the views (including norms) and practice of agents (Ramstad, 1986). A holistic definition looks more like a dialectal argument between generality and specificity, taking into account history, institutions and territorial context, than an omni-valuable formula as is provided in an essentialist definition. Holism is typical of specific currents in institutional economics (for example, old American institutionalism, 
and in particular John Commons' work). Therefore, institutional economics and the related economic sociology may be significant contributors to the definition of the 'local social economy'.

We do not treat both types of definitions as 'mutually exclusive' but as complementary, each having its specific analytical role. The essentialist definition provides a guideline for contextual analysis, whose result (the holistic definition) is intended in its turn to reshape the former, while offering a richer source for comparative analysis of typical cases.

\section{A Contemporary Approach to the Definition of the Social Economy}

Essentialist definitions distil a number of categories needed to determine the greatest common denominator of phenomena or concepts that are identified as being similar or, in a limited number of cases, even identical. In the case of the social economy, these could be: satisfaction of basic and sustainable needs, the democratic institutionalisation and organisation (governance) of production systems, reciprocity and redistribution in production and exchange relationships (see Moulaert and Ailenei, in this issue). But the inconvenience of essentialist definitions is that they are context-alienated and therefore detached from real situations, with a tendency to impose path-independent norms for the social economy; norms that are often rejected by the community that is seeking development.

Holistic definitions, in contrast, take context and trajectories of development into account. Their rationale is inherently institutional with

—institutions as contexts of development and development action;

- culture as a mode of communication and collective behaviour;

- and also institutions as the building blocks of a governance system, institutions in their various meanings of habitus, legal and administrative systems, formal and informal behavioural rules.
Therefore, holistic definitions more than essentialist definitions stress the role of institutions and governance in defining the social economy. A holistic approach will also address the historical context of the contemporary social economy and possibly compare it with that of, for example, the social economy within the welfare systems as observed in co-operative pre-Fordist or mutualist Fordist Europe. But the methodological inconvenience of a holistic definition is that, because of its iterative nature, it becomes lengthy and, for positivist social scientists, a boring or 'non-scientific' narrative. Therefore, in scientific practice, a confrontation between complex holistic and simple-methodologically disciplining?- - essentialist definitions could be quite relevant, for pedagogical and analytical reasons.

Because of the affinity of holism with institutional analysis, and its concern with the interplay between normative and analytical approaches (as in pragmatism), the definitions of the social economy provided here focus very strongly on the governance dimension of the social economy, which involves both democratic control and associative forms of co-operation of production and allocation systems. Various questions are examined

-What is the definition of governance and good governance in economics, and especially in institutional economics and economic sociology-i.e. the only (sub) fields in the economic discipline that really deal with governance?

- How can the definition of the social economy benefit from the more essentialist analysis in neo-institutional economics and the way it treats governance (market, hierarchy or in between)? ${ }^{2}$

-Which normative and analytical dimensions should be included in essentialist and holistic definitions of the social economy and its governance?

\subsection{The Problems with Defining Governance in Economics}

Governance is a central issue for social economy because of its particular focus on 
the articulation of socioeconomic relations. If the economy is to be analysed not only through market mechanisms, but also in consideration of the institutional setting of social relations, it means that the search for co-ordinated coherence and interaction between the various agents and agencies involved in economic life is of the utmost importance. The concept of governance reflects this concern. As a start, we provisionally define socioeconomic governance as the social relations which govern the functional organisation of an (socio) economy or some of its components.

There are two important streams of literature dealing with governance problems in economics

—institutional economics; and

- economic sociology.

These approaches are analysed in this section because they offer particular views on socioeconomic relations and their co-ordination. The guideline for reading both these literatures is in particular the need to consider the diversity of organisation principles and types of social relation, as they will be relevant to defining the governance of social economy agents and structures.

Institutional economics. Without being exhaustive, institutional economics is a very broad field that is historically, ideologically, theoretically and methodologically divided (Villeval, 1995; Moulaert and Lambooy, 1996). Among mainstream economists, the best-known line of thought is the so-called neo-institutional or new institutional economics (for a survey, see Eggertsson, 1990), whose main exponent is Oliver Williamson with his transaction cost theory. This contemporary theory wrongly attributes its foundations to the work of John Commons who provided a socially embedded approach to various types of transaction (Commons, 1934/1961), which is totally different from neo-institutional economics. The main merit of Williamson's transaction cost theory is that it has abandoned the full-information rational economic behaviour assumptions in favour of a model of individual economic behaviour based on bounded-rationality and transaction cost control. However, the institutional theory that is built on the basis of the transaction cost paradigm is only partially capable of explaining the collective dimensions of the development, building and destruction of institutions; for example, it does not take into account the rise and destructive influence of power relations on the development of institutions as well as on society as a whole.

Other lines of thought in institutional economics, however, are of greater relevance to our definitional work. The German Historical School laid the ground for the contemporary theories of the state, for the theories of stages of development and for the role of culture and institutions in local development (Nussbaumer, 2002). The German Historical School (and in particular Schmoller, 1905) is considered as one of the founders of methodological holism or collectivism, and in this respect contrasts with the Austrian School that is considered as the main centre of methodological individualism. The content of the Methodenstreit or methodological quarrel between Schmoller (1905) and Menger (1883) is still today a useful mirror highlighting the difference between methodological holism and methodological individualism and how they relate to the various currents in institutionalism (Hodgson, 2001).

Today, in economics, neo-institutional economics is often presented in contrast to contemporary institutional economics or new institutionalism, with G. Hodgson as its best-known international scholar. This 'close labelling' of both neo-institutionalisms (neoinstitutional economics versus new institutionalism) becomes quite confusing, but the distinctions between both approaches are very significant. Table 1 provides an eclectic comparison of neo-institutional economics and new institutionalism. It is important to point out that the new institutionalism is the descendant of the old US institutional school and the German Historical School, because of its historical approach, its historical and contextual definitions of institutions 
Table 1. Analytical and methodological features of institutional economic theories relevant to social economy and governance debate: an essentialist summary!

\begin{tabular}{|c|c|c|}
\hline Theory & Theoretical premises & Methodological observations \\
\hline German Historical School & $\begin{array}{l}\text { Culture } \\
\text { Stages of development } \\
\text { Collective action-state }\end{array}$ & $\begin{array}{l}\text { Historicism: general laws versus } \\
\text { historical specificity } \\
\text { Methodological collectivism }\end{array}$ \\
\hline Austrian School & $\begin{array}{l}\text { Culture } \\
\text { Micro-economic foundations of } \\
\text { collective behaviour }\end{array}$ & Methodological individualism \\
\hline Old US institutionalism & $\begin{array}{l}\text { Institutions } \\
\text { Habit of thought, role of praxis } \\
\text { Transactions as socially } \\
\text { constructed relation }\end{array}$ & $\begin{array}{l}\text { Evolutionist metaphors } \\
\text { Pragmatism } \\
\text { Holism }\end{array}$ \\
\hline $\begin{array}{l}\text { Neo-institutional } \\
\text { economics }\end{array}$ & $\begin{array}{l}\text { Transaction as exchange between } \\
\text { individuals } \\
\text { Limited information }\end{array}$ & $\begin{array}{l}\text { Methodological individualism } \\
\text { Minimisation of transaction cost } \\
\text { in uncertain environments }\end{array}$ \\
\hline $\begin{array}{l}\text { New institutionalism } \\
\quad \text { (evolutionism, } \\
\text { regulationist school) }\end{array}$ & $\begin{array}{l}\text { Endogenous consumption and } \\
\text { innovation economic dynamics } \\
\text { Evolutionist view of } \\
\text { development } \\
\text { Role of institutions in } \\
\text { development and regulation } \\
\text { Culture, science and learning }\end{array}$ & $\begin{array}{l}\text { Historically, institutionally and } \\
\text { territorially contextual analysis } \\
\text { of socioeconomic interaction }\end{array}$ \\
\hline
\end{tabular}

(commons), its critical and pluralist use of the biological metaphors on evolution (evolutionary economics is part of the new institutionalism) and the endogenous status of innovation, preference scales and institution building (Hodgson, 1988; Moulaert and Lambooy, 1996). In addition, new institutionalism has a strong affinity with economic sociology (Swedberg, 1987).

Another important line of thought in new institutionalism is regulation theory, an offshoot of structural Marxism (Althusser), radical theories of the state and, indirectly, 'old' institutionalism and the German Historical School (Boyer, 1987; Villeval, 1995; Baslé, 1995; Moulaert and Swyngedouw, 1989; Jessop and Ngai-Ling Sum, 2006). Recently there has been a rapprochement between regulation theory, evolutionary economics and economic sociology, in the sense that regulation theory has provided appropriate vocabulary for other institutional and socioeconomic approaches.

In any case, a theory and definition of governance in new institutionalism encompasses many more dimensions than in new institutional economics.
Neo-institutional economics on governance. Neo-institutional economics is defined here as the broader transaction cost and property rights school, that has tried to complete or replace the price allocation system theory by a broader allocation logic based on the exchange of property rights under a regime of minimising transaction costs. ${ }^{3}$ In this way, neo-institutional economics both compares and tries to integrate the specific logic of various institutional relations into a unifying theory of transactions. The transaction becomes the elementary institutional exchange, the building-block of all institutions; efficient institutions are those that curb overall transaction costs.

In neo-institutional economics, the debate on governance is focused on the tension between market and hierarchy-and the in-between form of 'economic co-operation'. 4 But to take this as the starting-point of the co-ordination and governance debate, is misleading, especially within a territorial context (Grabher, 1993). For in neo-institutional economic analysis, market, hierarchy and co-operation are presented as comparable categories of co-ordination and governance 
Table 2. Economic-functional organisations and their social structuring

\begin{tabular}{|c|c|c|}
\hline Functional organisation & Structuring principle & Elementary social relation \\
\hline \multirow{4}{*}{$\begin{array}{l}\text { Firm } \\
\text { Market } \\
\text { Household }\end{array}$} & Division of labour & Teamwork \\
\hline & Price system & Exchange-transaction \\
\hline & Reproduction & Teamwork \\
\hline & \multicolumn{2}{|c|}{ Mode of interaction } \\
\hline Power relations & Co-operation & Competition \\
\hline \multirow{3}{*}{ Hierarchy } & Principal-agents & Market exploitation \\
\hline & Exploiter-exploited & Unequal exchange \\
\hline & & $\begin{array}{l}\text { Economic rivalry } \\
\text { between partners in } \\
\text { household }\end{array}$ \\
\hline $\begin{array}{l}\text { Free choice of entry- } \\
\text { equal power }\end{array}$ & $\begin{array}{l}\text { 'Co-operative' ... based } \\
\text { on solidarity and } \\
\text { reciprocity }\end{array}$ & Free market-Fair trade \\
\hline
\end{tabular}

Note: Entries in central boxes are illustrations, not mutually exclusive types.

of economic functions. In fact, they are not because, as we will see now, they refer to different functional logics.

Most economists will agree that a market is an allocation system in which the price system is the main discriminant. A market refers to a particular type of economic function-i.e. the allocation of goods and services through a price system. Other economic functions are production, consumption, etc.

Hierarchy, however, is a principle of organisation of social/human relations, whatever the economic functional institution it is applied to-a market, a firm, a social service - a financial circuit can be hierarchically organized to a larger or smaller extent. In fact, hierarchy refers to a form of (social) co-operation-i.e. co-operation that is partly structured by the exertion of power by agents over others. Free cooperation and hierarchy are therefore more comparable categories than market and hierarchy.

Clearly neo-institutional economics has confused the following distinctions

-Distinctions between the various 'real' economic functions. Examples in the real sphere of the economy are production-allocation/ exchange-consumption-investment.
-Distinctions between different principles of organisation: it is very hard to provide a typology of principles of organisation without referring to a specific organisation (or institution): an enterprise or a firm, a household, a market. These are organisations referring to economic institutions: market (allocation/exchange), enterprise (production/exchange/investment), household (consumption/exchange).

In reality, various types of functional organisation have their own logic and therefore their own principles of organisation. To provide an appropriate definition of an economy, in our case a 'social' economy, these various logics should be distinguished and the complementarity between them fully recognised. The intrinsic principle of organisation for each of these functional organisations can be simplified as shown in Table 2.

However, there also exist more generic principles of interaction between agents (see Table 2), principles that are not determined by the nature of the economic or social function, but by human interaction properly speaking: co-operation and competition, or solidarity and exploitation-for example, can play a part in various types of functional organisation and interfere with their basic structuring principles. 
Examples include a division of labour ruled by competition and/or co-operation and/or hierarchy; a household normalised by relations of solidarity and/or reciprocal exploitation. Arising here are germs of ideas which help to distinguish the 'social' from the 'non-social economy'.

There are also ethical principles, behavioural rules and political choices about (re)distribution and reciprocity. In neoinstitutional economics, these principles play a minor role. The sole ethical principles are minimisation of transaction costs and sanctioning of opportunism-minimalist norms compared with those needed to 'govern' social economy agents and structures (see Figure 1).

Economic sociology and social economics. Many of the mentioned missing elements or faulty lines of reasoning found in neo-institutional economics today, had already been signalled by economic sociology (Swedberg, 1987) and social economics long before the 'new' economics came into being. As illustrated very clearly by Swedberg (1987), many developments in both fields have the same roots: the German Historical School, the dialectics between functionalism and structuralism in Europe and the US, the founding fathers of sociology (Max Weber, Emile Durkheim, etc.), Polanyi's 'great transformation'...

Neo-institutional economics could have meant a revolutionary turn-about of market analysis, showing that it involves not only the price system but also relations of power, co-operation or exploitation. But because of the obsession to write a 'unifying' transactional theory of the firm, this major opportunity was missed. In fact, the prime functional logic of a firm is to produce, to be creative and to organise a division of labour. A transaction logic can only play a part in the organisation of the firm and its creative functions on the condition that this logic is confronted with other principles of allocation, the functional diversity and the generic principles of human interaction within the firm.

Figure 1. The paralysed triangle of neo-institutional economics.
Within economic sociology, various debates are relevant to the definition of the social economy at the local level

- The institutional interpretations of firms and markets. Firms and markets should not be studied as abstract categories, but as concrete institutions with a history and social dynamics (see Hodgson, 1988).

- The debate on principles of allocation (price system, central distribution, barter) (see, for example, Mingione, 1991).

- The debate on the democratic and social firm and the role of associativity, showing how various forms of social interaction can usefully replace or complete market failures (see the literature on the 'third sector': Lipietz, 1999; Laville, 1994).

- The debate on ethical production and fair market exchange, (re-)introducing reciprocity and equity in consumptive behaviours (production and distribution of value, fair trade-see, for example, Smelser and Swedberg, 1994; Favreau and Fréchette, 2000).

As in neo-institutional economics, the categories used in economic sociology do not always belong to the same family of logic: a market is an allocation/exchange system, whereas reciprocity and associativity refer to generic principles of human organisation, with or without ethical connotation. This is why in economic sociology, as in new institutionalism the various logics of institutional dynamics (functional, social organisational, ethical and political) are examined in relation to each other within a concrete historical and institutional context. This contextual analysis indeed allows for the identification of the truly applied principles of social interaction.

\subsection{Defining 'Social Economy' and its Governance: Concept and Context}

To develop scientifically acceptable definitions of the social economy and the type of governance that goes with it, we mobilise the variety of logics of economic functions, the principles of social/human organisation and the way behavioural rules, ethical 
principles and political viewpoints underpin or interfere with them.

Let us recall that we use two meanings of the concept 'definition': the essentialist or generic meaning commonly used in (positivist?) social science; and the institutional or holistic definition as used in institutional economics (Commons, 1934/1961; Ramstad, 1986; see previous section). We argue that the holistic definition is analytically more useful because it contextualises (historically, institutionally, territorially) phenomena and concepts and provides an answer to the typical duality between normative and descriptive analysis in social science. However, the essentialist definition is maintained as a general referential among analysts of social phenomena, because it contains categories that are generally 'recognised' by social scientists, even if the concrete (contextual, historical) varies significantly among them. It can be considered as a preliminary step towards a holistic definition, that orients the contextual approach of social phenomena-for example, it can be used as a mode of selecting themes for holistic definitions.

Essentialist definition. Stringing together the distinctions made in the critical literature survey of institutional economics and economic sociology, and with reference to the analysis of social economy and its governance as reviewed in Moulaert and Ailenei (in this issue), the 'essentialist' dimensions shown in Figure 2 can be distinguished.

It is obvious that even an essentialist definition of the social economy should include the basic economic functions of production

\begin{tabular}{|c|c|c|}
\hline \multirow{3}{*}{ 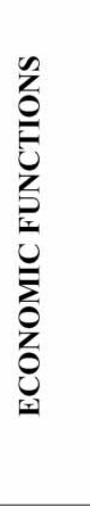 } & $\begin{array}{l}\text { Production/firms: } \\
\text { Division of labour } \\
\text { (1) }\end{array}$ & \multirow{9}{*}{$\begin{array}{l}\text { Combining economic functions (1), (2), (3) with } \\
\text { organizational principle (5) 'Competition' defines the } \\
\text { capitalist market economy. } \\
\text { But the market (5) can be more cooperative (4) or more } \\
\text { based on a hierarchical organization of dominance and } \\
\text { dependence (6) as in a system with hegemonic finance } \\
\text { capital or uncontrolled multinational production } \\
\text { systems. } \\
\text { A combination of functions (1) } \rightarrow \text { (3) with the collective } \\
\text { application of norms (7) } \rightarrow(9) \text { in the competitive } \\
\text { market system (5) could delimitate the 'social' market } \\
\text { economy. } \\
\text { The social economy purely speaking would then replace } \\
\text { (5) by (4) (8) 'Voluntary Cooperation'. The } \\
\text { combination of the latter two lays the ground for a broad } \\
\text { essentialist definition of the social economy. }\end{array}$} \\
\hline & $\begin{array}{l}\text { Allocation: price } \\
\text { system, barter, } \\
\text { central distribution } \\
\Leftrightarrow \text { Satisfaction of } \\
\text { needs (2) }\end{array}$ & \\
\hline & $\begin{array}{l}\text { Households: } \\
\text { reproduction - } \\
\text { including (mass) } \\
\text { consumption(3) }\end{array}$ & \\
\hline \multirow{3}{*}{ 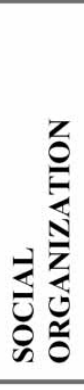 } & Cooperation (4) & \\
\hline & Competrioñ (ग) & \\
\hline & $\begin{array}{l}\text { Dominance/ } \\
\text { Dependence (6) }\end{array}$ & \\
\hline \multirow{3}{*}{$\sum_{\substack{n \\
0}}^{\infty}$} & Re-distribution (7) & \\
\hline & Reciprocity (8) & \\
\hline & Sustainability (9) & \\
\hline
\end{tabular}

Figure 2. Dimensions permitting essentialist definitions of (social) economies. 
and allocation, but should also incorporate the household sector with its functions of reproduction in the larger (education, integration into existential communities) and in the stricter sense (for example, through consumption and domestic production). The ethical values, behavioural rules and political views towards which these functions should be geared, and how the interaction between agents is inspired or codified, are also essential.

Therefore, for the time being, we could live with the following essentialist definition of the social economy: the social economy is that part of the economy (or the complement to the 'co-existing' other economy) that

-organises economic functions primarily according to principles of democratic co-operation and reciprocity ...

- guaranteeing a high level of equality and distribution, and organising redistribution when needed ...

- in order to satisfy human basic needs, in a sustainable way.

Sustainability refers to ecological, social justice and governance logics (see BuckinghamHatfield and Evans, 1996).

Several observations can be made with regard to this definition. First, the definition of governance, provides a wider range of logics than in neo-institutional economics. Organisation and governance are at the same time dependent on the specificity of the economic functions and of the relations between them, on the multiplicity of principles of social organisation (including modes of allocation) and on the multiplicity of behavioural norms that can be of an ethical, political or just 'conventional' nature. Note that this definition does not exclude governance through market co-ordination, on the condition that this respects principles of voluntary co-operation between and within marketagents-almost in the social liberal sense of the term-and reciprocity in exchange (as, for example, in fair trade).

Secondly, it remains an 'essentialist' definition, disconnected from historical, institutional and territorial contexts. These contexts are highly relevant for understanding the nature of the social economy and its governance within particular territorial and institutional conditions. For example, the issue of the articulation between various scales of governance of the social economy, presented at the beginning of this paper as a hot topic in the social economy debate, is only implicitly present in this definition.

Thirdly, and as a consequence, the flaws of essentialism are particularly visible in the relation between principles of social organisation and ethical principles. It is well known that mainstream economics in its essentialist approach tends to confuse normative with analytical models. In this way-for example, it often mixes actual consumer behaviour with behaviour predicted on the basis of satisfaction of individual utility levels: actual behaviour is exclusively interpreted as the outcome of this type of rational (instrumental) economic behavioural norms. Of course, in reality normative principles for behaviour and actual consumer behaviour affect each other; but actual behaviour is the result of the interaction between individual and social processes. Even if rational principles lie at the basis of human agency, actual behaviour will reflect a 'mediated' rationality, the outcome of which is only a bleak reminiscence of the 'ideal' rationality (Moulaert and Nussbaumer, 2003).

Another confusion may arise when looking at co-operation. According to Kropotkin (1902/1972) — and most mainstream economists would disagree with this-co-operation is as much a foundation of economic behaviour as is competition. In other words, human progress is not only based on competition but on co-operation as well. And this is not only a consequence of an upgrading of human existential ethics, but of the very nature of real human behaviour which, as shown in economic anthropology, forms a mixture of competition and cooperation from the beginning. Moreover, as we have signalled already, co-operation can be forced upon agents through power exertion, but it can also be based on free choice or on reciprocity in human interaction. 
The problem of the interaction between actual organisational principles and ethical considerations for the future could be solved by use of holistic definitions for the social economy and its governance. The main reason for this is that holistic definitions are 'iterative': they analyse how phenomena originate and develop. This also holds for ethical principles and behavioural rules.

Holistic definitions. If the essentialist definition of the social economy already has a high governance content, it is ahistorical in the sense that it uses contemporary abstract concepts that should be applied to various stages in the development of the social economy; and, more specifically, it is uninstitutional because it does not consider the creation and development of institutions that have enabled the social economy or the reproduction of behavioural principles of reciprocity and redistribution.

The holist definition of social economy, in contrast, cannot be posed without understanding of the contextual (historical, social cultural, etc.) determinants of social economy. In other words, social economy as defined through the holistic approach, can be different according to time and space, because the forms of organisation, structuring principles and economic functions may take on a very different shape. For instance, the communitarian economy in America is very different from the solidarity economy (économie solidaire) in France. Both belong to the social economy, but the very context in which each unfolds requires a different definition of what it really is. To keep the reader in tune with our endeavour, we provide a brief summary of the holistic approach in social science and how it perceives the role of definitions. The summary is mainly based on Ramstad (1986) where he provides a Hineininterpretierung of the institutional economist John Commons' scientific approach. In his article he refers to the founding fathers of holism and its introduction into economics. We only present the main lines of the holistic approach and do not go so far as, for example, John Commons in his definition of 'institution' (Commons, 1934). We also occasionally adapt the terminology to contemporary language usage.

Following Diesing (1971), Ramstad considers the production of holistic knowledge as follows. To make it more tangible to the reader, we will interstice the argument with themes and relations found in the social economy. (We have no space here, however, to provide a fully fledged holistic definition of a social economy for a particular system.) Holists employ a part-whole mode of apprehending reality.

Reality is conceptualized as an integrated whole, a unity, not as a set of logically separable structures and processes ... There is no sharp distinction between the empirical and logical nature of things. Meaning, therefore, is linked to the context; entities or activities are assumed to be truly comprehensible only in their interrelationships with other entities or activities (Ramstad, 1986, p. 1071).

The researcher selects an analytical theme (such as people with basic housing needs) within a sub-system (such as an urban neighbourhood), which he first analyses for this sub-system, then for others. He examines whether the theme is generally relevant for all sub-systems and verifies its generality but also the specific differences for the theme within each sub-system. The approach that is used is comparative [in space, in time ...]. A typology of the theme and its variants is developed. For housing in urban neighbourhoods, this means that an indicator and a typical behaviour for people in need of social housing will be determined. The need for housing will be expressed differently from neighbourhood to neighbourhood, depending on housing provision systems (public or private, legal administrative institutions, functioning of housing markets, etc.).

Once one theme is empirically established, the researcher looks at others and the linkages between them in the various sub-systems. "The researcher tries to accomplish the linkages, the interconnectedness that constitutes the system's ... wholeness" (Ramstad, 1986). 
A theme then becomes a tentative hypothesis that can be 'tested' for a wide variety of cases through "contextual validation" as Diesing (1971, p. 147) calls it. The housing needs theme becomes empirically established once it has been contextually recognised for the different neighbourhoods. Another theme then is how housing needs affect people's expression of a demand for housing. This is then again established across neighbourhoods-i.e. by looking at the 'voice' role of housing associations, neighbourhood committees, local estate agencies, social housing organisations, etc. How do these agents connect to the housing needs of the local people? This linkage between both validated themes (housing needs, validated mediated demand) will then become the building block of a network of themes that will provide a pattern of the dynamics of the local social economy.

Several validated themes can be connected into a network and interpreted as being part of a pattern, the holist theory.

As the holist labours to improve the pattern model, he simultaneously strives to refine the associated typologies he is employing to interpret a specific system (Ramstad, 1986, p. 1071).

The role of individual cases, in their context, is as important as that of the 'general' pattern. A typology can be completely turned upside down in the light of a few powerful idiosyncratic cases.

Definitions in holism are usually quite complex, because they take into account the variety of themes within the contexts provided by the various (sub)systems, in their time and space patterns. Features of essentialist definitions are present; they often instruct the selection of themes or concepts, but these concepts will shade off rapidly into a series of variants, circumstances, aspects, standpoints and relations or contrasts with other concepts. And no such holistic 'definitions' will pretend to be complete; there is always more to be said and discovered (Diesing, 1971, p. 211).
The hasty observer may argue that the holistic definition sounds more like a theory, as positivist social scientists would call it, than a definition. But in fact this comparison does not hold, because holistic definitions transform the abstract nature of concepts into real themes, something that does not happen in positivist theories, where the nature of the concepts does not change by linking them to each other.

Returning to our 'mission', the definition of the social economy and its governance, the holistic approach will select themes from Table 4 and examine whether they can be materialised in various social-economic systems or in their components (regions, localities, cities, neighbourhoods, etc.) within their specific contexts. For example, the LETS system: how does it operate in the various neighbourhoods in a sample of European cities? To examine its operation, its various 'themes' must be examined. Which services and commodities are involved? Which type of exchange relationship? Which behavioural rules? Then, once the LETS theme is validated for a number of neighbourhoods (a neighbourhood as a sub-system), and the typology of variants established, the next step is to examine the links with other themes of the social economy, such as democratic management in small artisan enterprises. ${ }^{5}$

Thus, bit by bit (theme by theme, link by link), the 'network' or 'pattern' of the local social economy will be discovered, together with its historical, institutional and territorial context-within a comparative framework, aligning a number of neighbourhoods, probably within different cities. And, a priori, depending on their relevance to analysis and strategy, the specific cases with particular experiences, strategies and institutions, will receive as much attention as the general patterns of the social economy in our sample of neighbourhoods. A holistic definition accepts the limitation of knowledge and attempts to by-pass it through plurality and confrontation, in opposition to essentialist unification and a priori universality. 


\section{Defining the Social Economy at the Neighbourhood Level: Holism, Social Capital and Empirical Analysis}

When addressing the social economy at the local and neighbourhood level, the functions, modes of organisation and behavioural principles (ethical, political, customary) that are considered as basic elements of the definition of the social economy show a variety of relations with the local context (history, institutions, territory). In the holistic approach, to understand this local context, to grasp the particularities of the themes and variants in the social economy and its institutions, the role of local culture and the way the local social space is articulated with other spatial scales, are very important. We will especially develop the role of culture, while recognising but not fully developing the argument about the key role of the interconnection between spatial scales in the development or destruction of the (local) social economy and its governance. For example, multiscalar governance plays a key role in reproducing the ethical foundations of a social economy at the local level. It is insufficient to design ethically and democratically correct modes of governance to guarantee the 'social-economic' nature of economic functions. Competition and dominancedependence relations at higher spatial scales-for example, can nullify democratic co-operation in local social enterprises. It is therefore important to examine the scalar tensions on the various economic functions and how they can be by-passed or transformed through institutional actions, politically established within a new multilevel governance system; there is no holistic definition of the local social economy without linking in the theme of social space-wide political struggle, policy and institutions favouring or hampering social economy initiatives.

Returning then to our main focus here-i.e. the role of culture in calibrating the local context of the neighbourhood social economy-following Commons and Ramstad, we want to stress the development of behavioural norms, modes of organisation and co-ordination between people, groups and teams as factors of the social economy.

In essentialist terms, we could say that the social economy at the neighbourhood level contains those agents and their neighbourhood networks that are involved in local production, allocation and domestic activity in which ethical principles of (re)distribution, reciprocity and sustainability determine their social organisation. Financial institutions can be part of the social economy, to the extent that they support or facilitate the operation of the other functions. And local networks include their own anchoring within broader spatial scales.

In holistic terms, the social economy receives a more realist institutional content, including the historical trajectories of economic functions, modes of social organisation, local institutions with multiscalar linkages and rules of collective action, which are partly the outcome of social and political struggle. Neighbourhoods with histories of artisan production, artistic activities or specific educational or vocational experiences and cooperative network building will be defined as such. The institutions that have grown up with these activities and their modes of social organisation are part-and-parcel of the holistic definition of the neighbourhood social economy, developed as a typology of variants around a context-proof analytical pattern. Ethical principles are no longer the deus ex machina for urban renaissance, but are part of the local development history. Where co-operation on more or less reciprocal grounds has been a mode of social interaction for a long time (for example, LETS), reciprocity is not just an ethical principle, but also an experienced mode of practical social functioning. Ethical rules can become norms for social relations within the social economy, which means that both the process of need satisfaction and its result should not only be considered as instrumental to wealth creation, but as criteria of the evaluation of development strategies. But if co-operation has not been a current part of local existence, it can sometimes be 'reinvented' by referring to its history in the locality, the neighbourhood or 
in related localities, as shown by the recent development of the solidarity financial circuit in the north of France, reactivating an old tradition of mutual help. The reference to the past and the revival of symbolic past experiences are important elements of a local social economy that includes elements of identity. ${ }^{6}$ In fact, it is much more logical to append a logic of learning and collective action to an institutional-holistic approach of social reality than to an essentialist reading, where themes are presented as ingredients of an abstraction only.

The holistic definition also includes changes in institutions, explained as responses to changes in social conditions. Lipietz' arguments about the 'économie solidaire' as the prodigal child of the 'économie sociale' fit here (Moulaert and Ailenei, in this issue).

The next two sub-sections offer two significant steps in defining the social economy at the neighbourhood level. The first takes a holistic reading of social capital at the neighbourhood level and confirms Forrest and Kearns' conclusion that only a contextual analysis involving various dimensions of the local culture is analytically relevant; the second explains how SINGOCOM has been a learning process in holistic analysis of the neighbourhood social economy in European cities.

\section{1 'Holistic' Definition of the Social Economy: The Importance of Social Capital}

The recent debate on the notion of social capital and its role in neighbourhood development strategies is highly relevant to the holistic definition of the social economy, and puts a strong stress on the role of culture. The difference is striking between what we could call in our jargon 'essentialist' and 'holistic' definitions of social capital. In addition, the debate confirms the necessity of combining a basic needs strategy with a social innovation strategy in setting up social economy strategies at the local level. There is substantial evidence to show that the local community plays an important role in the production of social cohesion, not only at the most local level, but also 'higher up'. The neighbourhood then becomes more than a place of routine activities (eating, sleeping, purchasing, etc.) or recreation or leisure, but also an arena where humans can express themselves, converse or rediscover their identity, their spirit of solidarity, and work on their connectedness with other networks such as in regional and national kinship, political, social support and economic interest organisations. $^{7}$

We know from the literature that the debate on the role of social capital in socioeconomic development is endless. It is not our purpose to have the final word; our goal is limited to pulling together the strands in the debate that deal with the role of social capital in the development of the local social economy. We are using the concept of social capital to show that there is a growing tendency to approach it only in its contextual and concrete forms (Forrest and Kearns, 2001). The concept, although very often interpreted in an essentialist way, is therefore of high potential relevance for a holistic approach to the social economy at the local level. We could say that, in our critical interpretation of the analytical use of the concept, we are much more in line with the contribution of the 'old' Italian school of economic sociology (Bagnasco and Trigiglia, 1985/ 1993)—which, in much more precise terms, has been working on the embeddedness of economic action in the social, cultural and political context as well as its historical development-than with the contemporary essentialist view of social capital.

For the purpose of our analysis, there are at least two links between social cohesion in deprived neighbourhoods and the social capital debate. First, there is the link between social cohesion in the neighbourhood and social capital. Secondly there is the role of social capital in the economic development of the neighbourhood.

To analyse these links, we clarify the concept of social capital, following DeFilippis (2001) in his criticism of Putnam (1993a, 1993b, 1995, 1996, 1998, 2000). Putnam defines social capital as

By analogy with notions of physical and human capital ... social capital refers to 
features of social organisation such as networks, norms and trust that facilitate coordination and co-operation for mutual benefit. Social capital enhances the benefits of investment in physical and human capital (Putnam, 1996, p. 34).

Several observations should be made about this definition in order to clarify the concept and its interest for the holistic definition of the social economy.

First, social capital is not 'held' by individuals and groups, but is part of the social relations between agents (Loury, 1977; Bourdieu, 1985; Coleman, 1988; DeFilippis, 2001). According to DeFilippis, Putnam confuses the concept of social capital with a particular interpretation of civil societyi.e. voluntary associations. In Putnam's view, the two categories always have a positive influence, based on trust, norms and common values, gearing people to act in the direction of the collective or general interest. This of course is not only a reductionist view of social capital, but also adopts the hypothesis of automatic positive impact of social capital on development action. Or even worse: this view easily leads to the conclusion that bad development results mean absence of social capital.

Secondly, for Bourdieu (1985) social capital is underpinned by economic capital. But social capital exists as an economic and a non-economic component (social interactions and power relations). We could even go further and argue that various types of capital in communities, whatever their territorial basis, are strongly intertwined with each other (Moulaert and Nussbaumer, 2003). When the economic capital is insufficiently developed-because of exploitation, unfair distribution of capital and income-social capital's 'effectiveness' will be affected.

Thirdly, local development trajectories affect social capital in various ways. Longlasting economic decline can paralyse social capital, both in the Putnamian and Bourdieu meaning of the term. But if social networks can survive the economic decline, they are usually transformed or hollowed-out, with the cultural identities of the neighbourhoods surviving, but the social relations disarmed. And with the unity of social and economic capital defended by Bourdieu, social capital may even expire.

Fourthly, following Moulaert et al. (2000), interaction between various types of capital (business, ecological, human, social or institutional) can have destructive or creative consequences. Long-lasting decline of private investments can negatively affect the development of social and human capital, and delay necessary collective actions to counter physical and ecological decay. But interaction between types of capital is not mechanical or deterministic, but contextual in the various holistic meanings of the word. Social and economic capitals do not automatically underpin each other. In pre-capitalist societies, or areas with limited industrial development, social capital can be geared to ecological sustainability and social culture, rendering a higher level of social well-being than in areas with a more developed business capital (O'Hara, 1998).

The consequences of this critical look at social capital and its role in neighbourhood development are meaningful for a better understanding of the real impact of a holistic definition of social innovation at the local level. To this end, we return to the view of social innovation and its double meaning as a structuring principle for social economy initiatives at the neighbourhood level. Social innovation becomes a proactive strategy for the innovation or revival of social capital, in interaction with other types of capital. For example, mutualist movements in France in the 19th century have inspired the creation of small investment groups that are based on trust and reciprocity. Social capital has been thereby reactivated in a contemporary way. To make social innovation work, multiscale, extra-territorial co-operation networks and empowerment strategies will be necessary. But these should be rooted in the institutional history of the neighbourhood and its embedding spaces.

Therefore, a holistic definition of the social economy at the neighbourhood level will include its (un)development trajectories, 
looking at the pattern model of the social economy (economic functions, social organisational, ethical and political dimensions) and taking into account the relationships to the neighbourhood culture and, more specifically, local modes of interaction that shape social interaction and the institutional capacity to address needs, while spelling out the typologies of specific institutional contexts and agencies.

\subsection{Holistic Definitions and Empirical Investigation}

In the SINGOCOM project, the ALMOLIN model is presented as a heuristic device for studying social innovation in governance in local communities at the local level (see Moulaert et al., in this issue). The governance of the local social economy is a significant part of this model. ALMOLIN seeks to understand the sources of innovative strategies in local development. It distinguishes a variety of factors that are at their roots: social philosophies and theories arguing in favour of bottom-up redevelopment strategies, processes of social alienation and exclusion against which innovative strategies were directed, movement-rooted policy and strategic views, social economy and grassroots-based strategies.

We observed that it is hard to separate visions, theories and practical experience. There are many reasons why we should not do so: visions and (social or political) philosophies have influenced theories and practice; new theories have provoked reactions by 'new' or 'reinvented' theories; certain experiences have occurred ad hoc, disconnected from any visions or political principles, or in reaction against them; but others are partand-parcel of far-reaching processes of alienation, resistance and change, etc.

Apparent or real disjunctions or conjunctions between philosophical views, theory and innovative community development can only be properly studied through a holistic approach. In the case of SINGOCOM, themes to be studied and related to each other in a pattern model, have been extensively listed before and constitute the core of the empirical research (Moulaert et al., 2005 in this issue). We prefer to dwell briefly on some of the 'practical' issues of empirical holistic research. We will definitely skip the traditional positivist counterarguments (and the never-ending discussions that follow), which attack the lengthy monographic style of holism and therefore leave few opportunities for true synthetic analysis.

First, there is the selection of themes. More than in previous explorations of holistic methodology, we would like to stress the role of meta-theoretical synthesis in the structuralrealist tradition as the structure within which themes should be defined (Storper and Walker 1983; Moulaert, 1987; Nussbaumer and Moulaert, 2005). Such a synthesis could indeed be the source for the selection of potential patterns that will constitute the holistic definition.

Secondly, the calibration of themes needs the combining of quantitative and qualitative data, quite often to be analysed 'over space and time'. Methodological progress to establish these combinations has not come very far; but this should not be an excuse to desist from holistic analysis-for example, by exploiting the complementarities between historical and spatial statistical analysis with well-structured case studies of local development experiences in general and social innovation practices in particular (a methodology for the former is presented in Moulaert et al., 2002, appendix).

Thirdly, is the combination of the pragmatist and the holistic perspectives. Methodologically speaking, revisiting the (meta) theoretical framework in the light of 'policy' and 'strategy' feedback makes sense: if the theory is to serve a better understanding of socially innovative dynamics and their potential for change, the feedback from 'practical action', its processes and impact, is important. However, a conflict of temporalities may arise by excluding typical statistical methods from this type of diachronic analysis, thereby favouring case study research, and stressing the role of participatory observation and policy opinions - and in this way increasing 
the vulnerability of this approach to mainstream positivist criticism.

\section{Conclusion}

The arguments in favour of holistic definitions do not mean that essentialist definitions of the social economy and its governance at the neighbourhood level would be out of place.

Holistic definitions reconstruct the historical, institutional and territorial links of local communities (neighbourhoods) and their development trajectories, by themselves, or as part of a wider territorial ensemble. In this, the analysis of the evolution of social and political visions, and their influence on concrete strategies with respect to socioeconomic development and its governance, can play an important part. Ethical norms, behavioural rules or political visions do not drop from the sky, but form part of the development trajectories of communities. They unfold through the multiscalar dialectics that embrace local and non-local struggling and bargaining as well as the capacity of the local culture to reuse norms of behaviour that are adapted to contemporary challenges.

In contrast, the advantage of essentialist definitions is that they are usually based on a number of generally recognised common denominators, even if in real contexts they take on different meanings. In a way, essentialist definitions provide the initial themes for a holistic approach. And often, as they integrate elements from previous analyses, they can also include initial components of pattern models. Essentialist definitions can therefore bring orientation to the meta-theoretical structures to be used in the construction of pattern models.

As argued by Forrest and Kearns (2001), by bringing the notion of social capital back to its concrete dimensions, we can establish a link between a generally accepted essentialist concept—but with different definitions - and its potential meaning for the study of social innovation in neighbourhood development in a holistic approach. The notion of 'social capital' reminds us of the necessary link between the revival of existing social potential and socioeconomic change; but, on its 'holistic' Bourdieu side, it also refers to the intrinsic interweaving with other types of capital, especially economic. In the study of social innovation in the governance of local communities, these methodological dialectics between instrumentality and interdependence of various types of capital reinforce the argument in favour of contextual (historical, territorial) analysis as a conditio sine qua non for potentially successful collective action and policy. By doing so, a direct link between holistic analysis and policy-relevant research is established; and this reminds us of the intrinsic link between holism and pragmatism, as stressed by Ramstad (1986).

\section{Notes}

1. In SINGOCOM, empowerment is presented as a third dimension of social innovation, in addition to institutional innovation. In this way, the researchers wanted to stress the particular meaning of 'empowerment' within the broader dynamics of institutional innovation.

2. There are of course various interpretations of markets in institutional economics (see Hodgson, 1988).

3. Within this corporate governance perspective, we preferred not to include public choice theory in this critical discussion of neoinstitutional economics.

4. The authors'view on the interaction between market and hierarchy differs from that of one of the referees, which we respectfully reproduce here

Aside from the economics of governance (which in part is surely about corporate governance and not just the state and civic society?), Williamson and others use the distinction to ask whether there are economic reasons, based on the internalisation of transactions costs, for organisational modes to be either contractual (i.e. a spot market relationship) as with a sub-contractor or commercial supplier of goods or specialist skills like accountancy, or internalised through hierarchical managementemployee relationships. This can and does apply in any sector (it is perfectly general) and in turn raises useful efficiency questions about organisational types and structures (for example, it can be used to analyse the efficiency of not-for-profit voluntarysector bodies, public-sector agencies and the private sector). 
5. One of the best introductions to LETS is Douthwaite (1996).

6. The importance of language, narrative, symbols, religious and immaterial elements is underevaluated in positivist approaches, although they bear significance and motivation potential for individuals and communities.

7. Guest and Wierzbicki (1999) wonder 'What connects people to one another in the same street?' (cited by Forrest and Kearns, 2001).

\section{References}

Bagnasco, A. and Trigiglia, C. (1985/1993) La construction sociale du marché (Italian 1st edn, 1985). Paris: Presses ENS Cachan.

BASLe, M. (1995) Antécédents institutionnalistes méconnus ou connus de la Théorie de la Régulation, in: R. BOYER and Y. SAILlard (Eds) Théorie de la regulation: l'état des savoirs, $\mathrm{pp}$. 31-39. Paris: La Découverte.

Bourdieu, P. (1985) The Forms of Capital, in: J. RichaRDSON (Ed.) Handbook of Theory and Research for the Sociology of Education, pp. 241-258. New York: Greenwood.

BOYER, R. (1987) La théorie de la regulation: une analyse critique. Paris: La Découverte.

Buckingham-HatFiELD, S. and Evans, B. (1996) Environmental Planning and Sustainability. Chichester: John Wiley \& Sons Ltd.

Coleman, J. (1988) Social capital in the creation of human capital, American Journal of Sociology, 94(supplement), pp. 95-120.

Commons, J. (1934/1961) Institutional Economics: Its Place in Political Economy. Vol I. Madison, WI: The University of Wisconsin Press.

DeFilipPIs, J. (2001) The myth of social capital in community development, Housing Policy Debate, 12, pp. 781-806.

Diesing, P. (1971) Patterns of Discovery in Social Sciences. Chicago, IL: Aldine-Atherton.

Douthwaite, R. (1996) Short Circuit: Strengthening Local Economies for Security in an Unstable World. Foxhole: Green Books.

Eggertsson, T. (1990) Economic Behaviour and Institutions. Cambridge: Cambridge University Press.

FAVreau, L. and Frechette, L. (2000) Économie sociale, coopération Nord/Sud et développement. Working Paper No. 2, Cahiers du CRISES, Montreal.

Forrest, R. and Kearns, A. (2001) Social cohesion, social capital and the neighbourhood, Urban Studies, 38, pp. 2125-2143.

GrabHer, G. (Ed.) (1993) The Embedded Firm: On the Socio-economics of Industrial Networks. London: Routledge.
Guest, A. M. and Wierzbicki, S. K. (1999) Social ties at the neighbourhood level: two decades of GSS evidence, Urban Affairs Review, 35(1), pp. 92-111.

Hodgson, G. (1988) Economics and Institutions. London: Polity Press.

Hodgson, G. (2001) How Economics Forgot History: The Problem of Historical Specificity in Social Science. London: Routledge.

Jessop, R. and Sum, N.-L. (2006) The Regulation Approach and Beyond: Putting Capitalist Economies in their Place. Cheltenham: Edward Elgar (forthcoming).

Kropotkin, P. A. (1902/1972) Mutual Aid: A Factor of Evolution. London: Allen Lane.

LAVILLE, J. L. (Ed.) (1994) L'économie solidaire: une perpective internationale. Paris: Desclée de Brouwer.

Levesque, B., Malo, M.-C. and Girard, J.-P. (1999) L'ancienne et la nouvelle économie sociale, in: J. Defourny, P. Develtere and B. Fonteneu (Eds) L'économie sociale au Nord et au Sud, pp. 195-216. Paris: Editions De Boeck \& Larcier.

LIPIETZ, A. (1999) Rapport final sur l'entreprise à but social et le tiers-secteur relatif à la lettre de mission du 17 septembre 1998 de Madame Aubry, Ministre de l'emploi et de la Solidarité, (http//perso.clubinternet.fr/lipietz/SOC/SOC_ AubryRapportFinal.html; accessed February 2002).

LOURY, G. (1977) A dynamic theory of racial income differences, in: P. WALlACE and A. LAMOND (Eds) Women, Minorities, and Employment Discrimination, pp. 153-188. Lexington, MA: Heath.

Menger, C. (1883) Untersuchungen über die Methode der Sozialwissenschaften und der Politischen Ökonomie inbesondere. Tübingen: Mohr.

Mingione, E. (1991) Fragmented Societies: A Sociology of Economic Life beyond the Market Paradigm. Oxford: Basil Blackwell.

MoulaerT, F. (1987) An institutional revisit to the Storper-Walker theory of labour, International Journal of Urban and Regional Research, 11(3), pp. 309-330.

MoulaerT, F. and Lambooy, J. (1996) The economic organisation of cities: an institutional perspective, International Journal of Urban and Regional Research, 20, pp. 217-237.

Moulaert, F. and Nussbaumer, J (2003) Die ökonomie der europäischen Grossstadt, in: W. Siebel (Ed.) Die Europäische Stadt, pp. 396-405. Berlin: Suhrkamp.

Moulaert, F. and Swyngedouw, E. (1989) A regulation approach to the geography of flexible production systems, Society and Space, 7, pp. $327-345$. 
Moulaert, F., Delladetsima, P., DelvainQUIERE, J.-C. ET AL. (2000) Globalization and Integrated Area Development in European Cities. Oxford: Oxford University Press.

Moulaert, F., Leontidou, L., Delladetsima, P. M. ET AL. (1992-94) Local development strategies in economically disintegrated areas: a proactive strategy against poverty in the European Community. Reports for the European Comission (DGV, Poverty III). Lille: IFRESI.

NussBaumer, J. (2002) Le rôle de la culture et des institutions dans les débats sur le développement local: la contribution de l'Ecole Historique Allemande. Unpublished $\mathrm{PhD}$ Thesis, University of Lille I.

Nussbaumer, J. and Moulaert, F. (2005) Soziale Innovationen in Regionen: welchen Einfluss haben diese auf die Qualität der Arbeit?, in: U. J. WILKEN (Ed.) Innovative Region durch Qualität der Arbeit. Frankfurt-am-Main: Campus Verlag (forthcoming).

O'HARA, P. (1998) Capital and inequality in today's world, in: D. BROWN (Ed.) Thorstein Veblen in the Twenty-first Century, pp. 171-188. Cheltenham: Edward Elgar Publishing.

Putnam, R. (1993a) Making Democracy Work: Civic Traditions in Modern Italy. Princeton, NJ: Princeton University Press.

Putnam, R. (1993b) The prosperous community: social capital and public life, American Prospect, Spring, pp. 35-42.
Putnam, R. (1995) Bowling Alone: The Collapse and Revival of American Community. New York: Simon and Schuster.

Putnam, R. (1996) The strange disappearance of civic America, American Prospect, 7(24), pp. 34-48.

Putnam, R. (1998) Foreword, Housing Policy Debate, 9(1), pp. v-viii.

Putnam, R. (2000) Bowling Alone: The Collapse and Revival of American Community. New York: Simon and Schuster.

RAMSTAD, Y. (1986) A pragmatist's quest for holistic knowledge: the scientific methodology of John R. Commons, Journal of Economic Issues, 20, pp. 1067-1105.

Schmoller, G. (1905) Principes d'Economie Politique. Paris: V.Giard et E. Brière.

Smelser, N. J. and SwedberG, R. (Eds) (1994) The Handbook of Economic Sociology. Princeton, NJ: Princeton University Press.

StORPER, M. and WALKER, R. (1983) The theory of labour and the theory of location, International Journal of Urban and Regional Research, 7(1), pp. 1-43.

Swedberg, R. (1987) Current Sociology. London: Sage.

Villeval, M. C. (1995) Une théorie économique des institutions?, in: R. BOYER and Y. SAILlARD (Eds) L'Ecole de la Régulation. L'Etat des Savoirs, pp. 479-489. Paris: PUF.

Williamson, O. (1973) Markets and hierarchies: some elementary considerations, American Economic Review, 63, pp. 313-325. 
Copyright of Urban Studies is the property of The Editors of Urban Studies. The copyright in an individual article may be maintained by the author in certain cases. Content may not be copied or emailed to multiple sites or posted to a listserv without the copyright holder's express written permission. However, users may print, download, or email articles for individual use. 